\title{
Indicators of Integrated Water Resources Management at the local level: Meknes as a case (Morocco).
}

\author{
Mohamed Ben-Daoud ${ }^{1, *}$, Aniss Moumen ${ }^{2}$, Ahmaed Sayad $^{3}$, Mohamed ELbouhadioui $^{4}$, Ali Essahlaoui $^{1}$, and Samir Eljaafari ${ }^{1}$ \\ ${ }^{1}$ Moulay Ismail University faculty of sciences, Meknes, Morocco \\ ${ }^{2}$ Ibn Tofail University, National School of Applied Sciences, Kenitra, Morocco \\ ${ }^{3}$ Regional Center of Education and training professions (CRMEF), FEZ, Morocco \\ ${ }^{4}$ Ecole Nationale Supérieure des Mines de Rabat, Morocco
}

\begin{abstract}
This work aims to develop integrated water resources management (IWRM) and conduct an IWRM implementation assessment based on the study area's indicators. In this way, we have adopted a participatory approach for IWRM indicators development. As for assessing implementation at the local level, a survey was conducted among water sector actors in the study area to collect opinions regarding their management mode. In terms of results, four categories of indicators were developed in consultation with participating stakeholders, and an assessment of IWRM implementation was carried out. This assessment shows that the current management system is generally medium and that there is a difference between stakeholders regarding their capacity to IWRM implement. Some needs were identified for the majority of stakeholders to meet the requirements of integrated water management fully. The final target is to apply the IWRM in Meknes city as a case study that will eventually allow us to evaluate the water management system developed based on these indicators.
\end{abstract}

\section{Introduction}

As an older concept IWRM, it was reinvented in the 1990s [1]. Thus, several organizations in the world have adopted the IWRM approach globally [2]. Besides, IWRM aims to balance water use, protection, and conservation of water resources [1]. Although IWRM emphasizes the watershed as a management unit, attempts have been made to IWRM implement at more local scales while respecting IWRM principles[1,3-6]. Furthermore, IWRM has been criticized by researchers, particularly concerning its implementation $[1,4,5]$. Therefore, this work has considered the sub-basin as a management unit to respond to the study area's specific problems. Moreover, the integrated water resources management currently concerns all actors, near or far, in the water sector. The context marked by population growth, rapid urbanization and industrialization, expansion of agriculture and tourism, and climate change places increasing pressure on water resources [7]. Therefore, establishing an adequate management system has proved necessary; this system must share data in a water information system [8]. Also, water data are intended to be integrated into an information system and develop relevant indicators. So, our works try to address an overview of IWRM indicators and their criteria. This study was conducted in Meknes city using a survey with water stakeholders based on the IWRM indicators. The results highlighted the strong points acquired towards integrated management and the weak points, which constitute an obstacle to achieving integrated water management objectives. This work aims to identify gaps in the current water management system at Meknes city and trace the avenues for improvement towards the establishment of an integrated and sustainable management system.

\section{Methodology}

The methodology is based on working meetings with stakeholders in the water sector at the study area level to identify the indicators deemed relevant for integrated management in the study area; thus, four categories of indicators have been identified. Next, a survey was carried out among the water stakeholders to collect their opinions concerning their management. In this sense, the actors (figure 1) surveyed are those acting in the water sector and have a close relationship with water resources in the study area. There are five proposals in each question concerning the questionnaire, which gives the scoring system the following aspect in Table 1. [9-11]. The data collected was then analyzed to extract the current management system results in the study area level. We carried out two analysis levels, the first concerns the contribution of the various actors to the implementation of IWRM, the second level concerns the analysis of the studied indicators.

*Corresponding author: bendaoud.mohamed304@gmail.com 


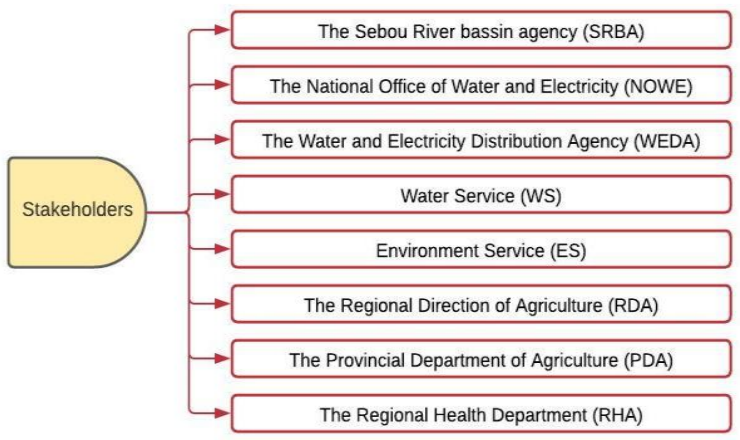

Fig.1. Interviewed stakeholders

Table 1. Scoring example for the first indicator: Technical

\begin{tabular}{lll}
\hline Score & $\begin{array}{l}\text { Quality } \\
\text { classes }\end{array}$ & $\begin{array}{l}\text { What techniques used in your } \\
\text { management actions? }\end{array}$ \\
\hline $\mathbf{5 / 5}$ & $\begin{array}{l}\text { Very } \\
\text { good }\end{array}$ & $\begin{array}{l}\text { Applicable techniques are } \\
\text { adapted to integrated water } \\
\text { management. }\end{array}$ \\
\hline $\mathbf{4 / 5}$ & Good & $\begin{array}{l}\text { Adapted techniques but more } \\
\text { difficult to apply }\end{array}$ \\
\hline $\mathbf{3 / 5}$ & Medium & $\begin{array}{l}\text { Few adapted and applicable } \\
\text { techniques }\end{array}$ \\
\hline $\mathbf{2 / 5}$ & Bad & $\begin{array}{l}\text { Few adopted techniques and } \\
\text { challenging to apply }\end{array}$ \\
\hline $\mathbf{1 / 5}$ & Very bad & No suitable technique. \\
\hline
\end{tabular}

\section{Study area}

The study area is located in north-central Morocco, about $140 \mathrm{~km}$ east of Rabat and $60 \mathrm{~km}$ west of Fez (figure. 2). The Lambert coordinates are: $\mathrm{X}=470$ to $510 \mathrm{~km}$ and $\mathrm{Y}=$ 320 to $380 \mathrm{~km}$. It is an area that stretches $35 \mathrm{~km}$ from east to west and 45 to $50 \mathrm{~km}$ from north to south.

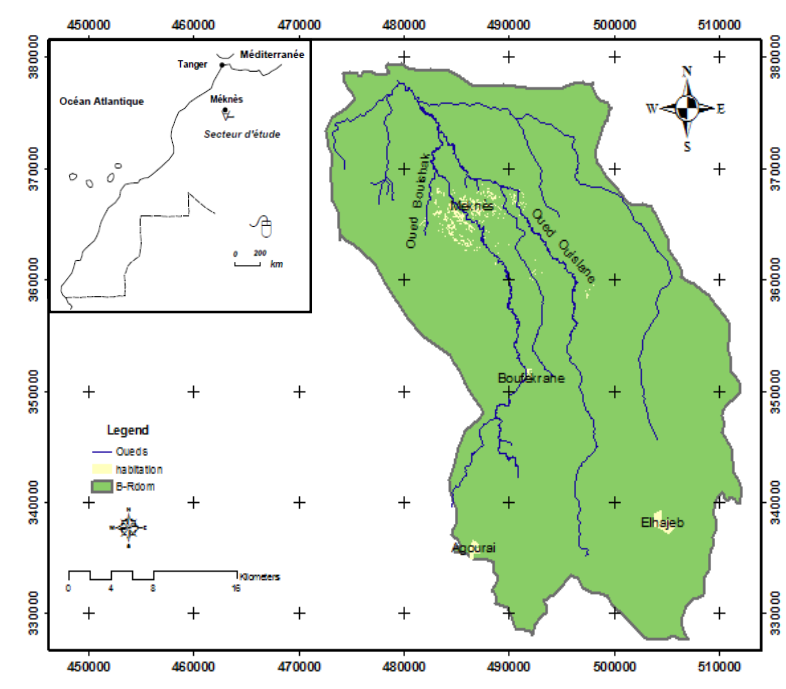

Fig. 2. Study area

This study area is considered agricultural and consumes groundwater resources, and offers significant environmental and economic potential.

\section{Results and discussion}

\subsection{Integrated Water Management Indicators}

Integrated water resource management indicators aim to assess the current water resources management system in the study area. In an environment of consultation with stakeholders, the indicator's proposal is mostly inspired by several works on integrated water management and its implementation at the local level [8,12-14].

The list of adopted integrated management indicators is not exhaustive, so it can be strengthened by improving data availability. The plan identified contains relevant key indicators concerning specific issues (evaluation tools, technical and financial resources) or the level of participation and integration (integration of uses, partnership, and consultation). We list below the adopted indicators in figure 3 .

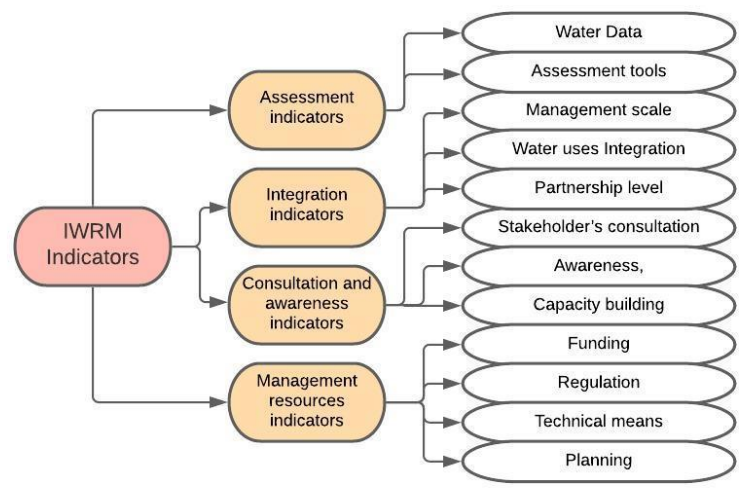

Fig. 3. Integrated management indicators

Although these indicators do not allow for an in-depth analysis of the water management system's problems, they nevertheless fulfill their primary function of providing more general data on the most critical issues related to the management system. Besides, for the choice of IWRM indicators, the crossing of the different elements, namely: The assessment, integration, participation, and available means, define the basic architecture of the water resources management system in the study area.

This approach will allow us to check whether the management system has the characteristics of IWRM and assess the elements to be reinforced to ensure the management system's finalization in the desired vision. Indeed four categories of indicators were used in order to understand better the state of the water management system: Assessment indicators; Integration indicators; Consultation

\subsection{Contribution of stakeholders in the integrated management system}

From the found results, it appears that the majority of actors are at medium to a satisfactory level, for some stakeholders, this in terms of contribution to integrated 
water management in Meknes. The Sebou river basin agency represents the actors who contribute to constructing an integrated management system, the national office of water and electricity, the water service, and The Water and Electricity Distribution Agency.

The other stakeholders have a secondary contribution due to the overlap between tactors' intervention and the lack of a common strategy between several stakeholders [1416]. So the majority of actors suffer from a lack of knowledge, funding, and assessment tools (figure 4).

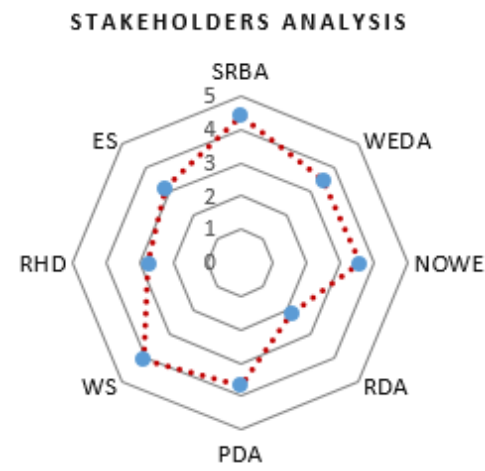

Fig. 4. Stakeholder's analysis

Indeed, most management structures are not perfectly suited to carry out integrated water management, which requires reflection focused on the players and the management of their resources to contribute together to integrated water resources management in their territory [11].

Moreover, a relationship may exist between the different studied variables; for example, the financial means indicator may have a relationship with the other indicators [8]. However, identifying and confirming this relationship between the variables is not the paper subject. It will be developed in another article when the data is all collected on the issue.

Stakeholders analysis: This analysis shows two main classes, the first in a class considered to be middle class bringing together the actors who are still far from integrated management with weak points in terms of technical and financial means, capacity building, and many other indicators. The second class considered good, grouping stakeholders who are more advanced and have integrated water resources management (figure 5).

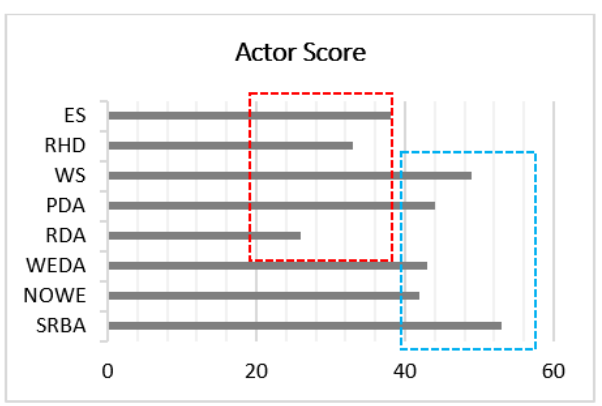

Fig. 5. Stakeholder's analysis
Indicators analysis: the indicators Analysis shows that the total score for all indicators is 27.3 while exceeding the average required for IWRM estimated at 24 , value without unit. The results also show certain actors' progress in some indicators, such as technical resources and water data. On the other hand, the indicators relating to capacity building and financial resources are still minor compared to other indicators.

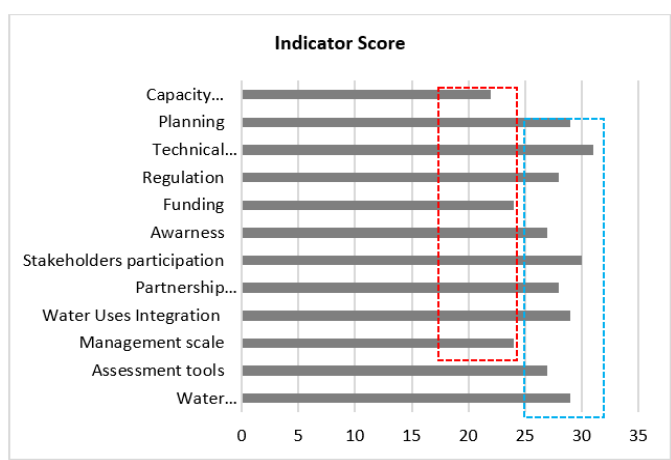

Fig. 6. Indicator's analysis

\section{Conclusion}

This work aims to provide an overview of IWRM indicators' importance and present a case study at Meknes city. Thus, the case study results highlighted the state of the adopted management system by actors. The results also show a difference from one actor to another in terms of the capacity to carry out IWRM, so some needs have been identified for the majority of actors to meet the requirements of integrated water management perfectly. To improve the indicators, it requires the mobilization of local stakeholders and establishing consultation and coordination mechanisms at the local level to make IWRM effective in the study area.

As for the indicator concept, the example drawn from this experience shows that indicators are relatively easy to develop. Nevertheless, it is often difficult to collect reliable, representative data to assess IWRM objectives' performance. It is also important to categorize the indicators in groups to reflect an overview and facilitate the quantification and aggregation of indicators into an index. This perspective will be the subject of further work to be developed within the same study framework.

\section{References}

1. A.K., Biswas. Integrated Water Resources Management: Is It Working? International Journal of Water Resources Development. Vol. 24, No. 1, 5-22, March (2008).

2. Global Water Partnership,. Lessons from Integrated Water Resources Management in Practice, Policy Brief 9. Stockholm (2009).

3. P.B., Moriarty, C.H. Batchelor, P. Laban, and H. Fahmy. Developing a practical approach to 'light IWRM' in the Middle East. Water Alternatives 3(1): 122-136-(2010). 
4. E. M. Akpabio. Assessing integrated water resources management in Nigeria: insights and lessons from irrigation projects in the Cross River Basin. Water Policy 9(2), 149-168.(2007)

5. L. E. Garcia.Integrated water resources management: a 'Small' step for conceptualists, a giant step for practitioners. International Journal of Water Resources Development 24(1), 23-36.(2008)

6. Petit, O. \& Baron, C. (2009).Integrated Water Resources Management: from general principles to its implementation by the state. The case of Burkina Faso. Natural Resources Forum 33(1), 49-59.

7. Global Water Partnership. Toolbox for IWRM: Global Water Partnership (GWP) (2007)

8. W. Medema, B. S. McIntosh, P. J. Jeffrey. From premise to practice: a critical assessment of integrated water resources management and adaptive management approaches in the water sector. Ecology and Society, Vol. $13\left(\mathrm{~N}^{\circ} 2\right)$ art 29. (2008)

9. B. Charnay. For integrated resource management in water in mountain territory. The case of the Giffre watershed (Haute-Savoie), Ph.D. in Geography, University of Savoie, 504 p;(2010)

10. M. F. A. Goosen. Environmental management and sustainable development. Procedia Engineering 33, p.6-13.(2012)

11. E.W. Dungumaro, N.F. Madulu. Public participation in integrated water resources management: The case of Tanzania. Physics and Chemistry of the Earth 28 p.1009-1014. (2003)

12. P. Jeffrey, M. Gearey. Integrated water resources management: Lost on the road from ambition to realization. Water Science and Technology Vol 53 (No 1), p.1-8. (2006)

13. D. Mazvimavi, Z. Hoko, L. Jonker, I. Nhapi, A. Senzanje. Integrated Water Resources Management (IWRM)-From Concept to Practice. Physics and Chemistry of the Earth 33-.609-613 p.(2008)

14. T. Sonoda, S. Khan.. IWRM For Flood Management at the River Basin Level: Strategic Strengthening of Flood Warning and Management Capacity of Pakistan. International Training Workshop of Stakeholders Capacity Building in Flood Warning and Management December 20-23, 2011, Islamabad, Pakistan.P.71 (2012)

15. C. Granjou, P. Garin. Organiser la proximité entre les usagers de l'eau: le cas de la gestion volumétrique $d u$ bassin versant de la Charente, Développement Durable et Territoires, Dossier $n^{\circ} 7$ : proximité en environnement. (2006)

16. M.D. Davis, J. Threlfall. Integrated Water Resource Management in New Zealand: Legislative Framework and Implementation. Journal of Contemporary Water research \& education issue 135 , p.86-99. (2006) 